Aksaray University
Journal of Science and Engineering
e-ISSN: 2587-1277
http://dergipark.gov.tr/asujse
http://asujse.aksaray.edu.tr

Research Article

\title{
Characterisation and Performance of Low-Density Poly Ethylene-Corn Flour Composites
}

\author{
Sameer A. Awad*, Eman M. Khalaf \\ Department of Chemistry, College of Education for Pure Science, University of Anbar, Anbar 31001, Iraq
}

\begin{abstract}
This study aims to investigate the effects of corn flour fillers on the mechanical and thermal properties and surface morphology of low-density polyethylene composites. Low-density polyethylene (LDPE) and low density polyethylene/corn flour (LDPE/CF) with different loadings of $\mathrm{CF}(5 \%-20 \% \mathrm{w} / \mathrm{w})$ were prepared in an internal mixer type Z-Blade mixer at $190^{\circ} \mathrm{C}$ and rotor speed of $50 \mathrm{rpm}$. Dynamic mechanical analysis (DMA), Thermogravimetric analysis (TGA), differential scanning calorimetry (DSC) and tensile tests were analysed to investigate thermal and mechanical properties. Tensile tests displayed an increase in the tensile strength and modulus with the increase of CF loadings. The results of DMA tests showed significant improvements for the storage modulus and glass transition temperature, $T_{\mathrm{g}}$. The results of TGA indicated that the addition of higher amounts of CF enhanced thermal stability.
\end{abstract}

\section{Keywords}

LDPE, CF, Thermal stability, Tensile strength, Storage of modules

*Corresponding Author: Sameer A. Awad, sameer.msc1981@gmail.com 


\section{INTRODUCTION}

A composite is mainly composed of a mixture of two or more of materials that have a different chemical composition, and that usually are insoluble in each other [1-3]. The significant aim of using these materials is to create better properties compared to that of the individual components. Polymer composites filled with natural additives were utilised sed as conventional composites and had a broad application [4-7]. Polymers with natural fillers are eco-friendliness because polymer - natural filler composites are more accessible to recycle, may be used as alternatives to existing products [8-10]. The incorporation of natural fillers into a polymer widely produced substantial changes in the mechanical properties of the composites. However, a problem appears when trying to mix natural fillers with plastics like polyolefins such as LDPE, HDPE, PP, and PVC [11-13]. This problem is one of the differences as a result of the hydrophilic nature of natural fillers such as corn flour. The mechanical properties of the untreated LDPE composites were observed, due to the reinforcing effect imparted by the natural fillers which allowed a uniform stress distribution from the continuous polymer matrix to the dispersed fibre phase [14-17]. However, there was a general improvement in the mechanical properties of the polymer composites in comparison to those of the polymer matrix [18-20]. Previous studies investigated of the DMA results showed that the incorporation of jute fibres into HDPE increased the modulus and stiffness of the matrix with reinforcing effect imparted by the natural fillers that allowed a higher degree of stress transfer at the interface [21-23]. This study aims to investigate the improvement of the thermal and mechanical characterisations of LDPE plastic reinforced corn flour $(\mathrm{CF})$ as a natural additive.

\section{MATERIALS AND METHODS}

\subsection{Materials}

Low-density polyethylene (LDPE) polymer was supplied from SABIC chemical company, KSA, The corn seeds were collected fresh from local farms.

\subsection{Corn Flour Treatments}

The corn seeds were dried by using a microwave oven at the temperature range of 60 to $70^{\circ} \mathrm{C}$ for 24 hours to remove the moisture after that they cracked to small parts and then passed through a molecular sieve (150-micron mesh size).

\subsection{LDPE Composite Preparation}

LDPE composites were melted and mixed with different ratios of corn flour filler in a shear mixer at a rate about $50 \mathrm{rpm}$ with the continued mixing for $7 \mathrm{~min}$ to achieve the homogenous between 
the CF and LDPE matrix. The mixture was poured out into metal moulds and compressed, starting from $20 \mathrm{~kg} \cdot \mathrm{cm}^{-3}$ and then increased to $100 \mathrm{~kg} \cdot \mathrm{cm}^{-3}$ within $7 \mathrm{~min}$. After $24 \mathrm{~h}$, the samples were removed from moulds and left for a day to make more curing.

\subsection{Characterisations}

\subsubsection{Mechanical tests}

The tensile tests were done on a Universal machine, model Instron 1130 tester, according to standard ISO 527-1, using a load of $1000 \mathrm{~N}$ and the test speed is $2 \mathrm{~mm} . \mathrm{min}-1$.

\subsubsection{Dynamic mechanical analysis $)$ DMA(}

Dynamic Mechanical Analysis (DMA) was applied out using a TA instruments model DMA2980. The dimensions of the samples were of $35 \times 9 \times 1.5 \mathrm{~mm}$. A heating rate was $10^{\circ} \mathrm{C}$ at a fixed frequency $(1 \mathrm{~Hz})$, and the range of temperature was between 30 to $150^{\circ} \mathrm{C}$.

\subsubsection{Thermogravimetric analysis )TGA(}

LDPE and LDPE-CF composite samples were tested by utilising TGA instruments type (TGA Q500; TA Instruments) under a nitrogen atmosphere. The temperature range was from 30 to $600^{\circ} \mathrm{C}$. All samples were tested at a heating rate of $10^{\circ} \mathrm{C} \cdot \mathrm{min}^{-1}$. The activation energy for decomposition $\left(E_{a}\right)$ was calculated utilising Horowitz-Metzger (HM) equation.

$\ln \left[\ln (1-\alpha)^{-1}\right]=E_{a}\left[E_{a} \theta / R T_{\max }^{2}\right]$

$\alpha=\frac{C i-C}{C i-C f}$

$\alpha=$ the decomposed fraction and is specified as $=/ C_{i}-C_{f}$.

$C=$ the mass at a temperature chosen, $\mathrm{C}_{\mathrm{i}}$ the mass at the initial temperature $\left(T_{\mathrm{ons}}\right)$ and $C_{f}$ is the mass at final temperature.

$E_{a}=$ the activation energy for decomposition.

$T_{\max }=$ the temperature at a maximum rate of mass loss.

$R=$ the universal gas constant

$\theta=T-T_{\max }$

Kinetic plots were made with $\ln \left[\ln (1-\alpha)^{-1}\right]$ versus $\theta$.

\subsubsection{Differential scanning calorimetric analysis (DSC)}

The thermal characterisation of LDPE and LDPE/CF composites were determined by using a TA Q-10 thermal analysis apparatus. The temperature range was used between of 30 to $220^{\circ} \mathrm{C}$ 
at a heating scan rate of $10^{\circ} \mathrm{C} \cdot \mathrm{min}^{-1}$ under a nitrogen atmosphere. In the first heat run, all samples were annealed at $220^{\circ} \mathrm{C}$ for $5 \mathrm{~min}$ to eliminate the thermal history. The degree of crystallinity $\left(X_{\mathrm{c}}\right)$ of LDPE and LDPE composites was calculated from the heat of fusion $\left(\Delta H_{\mathrm{m}}\right)$ of the second heating cycle with the following relation.

$X_{c}=\left(\frac{\Delta H_{m}}{(1-\varnothing) \Delta H_{m}}\right) \times 100$

Where, $\Delta H^{\circ}$ m is the heat of fusion for $100 \%$ crystalline LDPE, which has taken $287 \mathrm{~J}^{-1} \mathrm{~g}^{-1}$. Subsequently, the samples were cooled to $40{ }^{\circ} \mathrm{C}$ at the rate of $10{ }^{\circ} \mathrm{C} \cdot \mathrm{min}^{-1}$ and cooling rates and the corresponding melting temperature $\left(T_{\mathrm{m}}\right)$, crystallisation temperature $\left(T_{\mathrm{c}}\right)$ and degree of crystallinity were recorded from the heating and cooling curves.

\section{RESULTS AND DISCUSSION}

\subsection{Mechanical Properties}

The results of stress-strain curves are exhibited in Figure 3. The tensile strength and modulus of elasticity were increased with the incorporation of CF contents of 5-20 wt.\% into the LDPE matrix. Table. 1 showed that tensile strength increased with adding a higher loading level (20 wt.\% CF) compared to that of pure LDPE matrix. The tensile strength of LDPE/5 wt\%, LDPE $/ 10 \mathrm{wt} \%$, and $20 \mathrm{wt} \%$ CF composites increased by $1 \%, 14 \%$, and $30 \%$, respectively. The tensile modulus of LDPE/ $5 \mathrm{wt} \%, 10 \mathrm{wt} \%$, and $20 \mathrm{wt} \%$ CF composites increased by $16 \%, 26 \%$, and 37\%, respectively, compared with PP matrix (Table.1). In contrast, elongation at the break decreased by $60 \%, 31.5$, and $14 \%$ of $20,10,5 \mathrm{wt} \%$ CF in LDPE matrix, compared to that of LDPE (Table 1). Overall mechanical results exhibited better tensile strength and modulus for the higher loading level (10 wt\%) CF into LDPE, compared with that of lower loading levels of CF and LDPE matrix.

Table 1. Mechanical properties of LDPE and LDPE composites

\begin{tabular}{llll}
\hline The samples & $\begin{array}{c}\text { Tensile strength } \\
(\mathbf{M P a})\end{array}$ & $\begin{array}{c}\text { Modulus of elasticity } \\
(\mathbf{M P a})\end{array}$ & $\begin{array}{c}\text { Elongation at Break } \\
(\%)\end{array}$ \\
\hline Pure LDPE & $25.8 \pm 3.2$ & $189.5 \pm 22$ & $9.5 \pm 0.8$ \\
LDPE / 5 \% CF & $26.2 \pm 1.5$ & $220.4 \pm 15$ & $8.2 \pm 0.5$ \\
LDPE / 10 \% CF & $29.5 \pm 2.7$ & $238.5 \pm 25$ & $6.5 \pm 0.2$ \\
LDPE / 20 \% CF & $33.5 \pm 2.5$ & $260.5 \pm 30$ & $3.8 \pm 0.7$ \\
\hline
\end{tabular}




\subsection{Dynamic Mechanical Analysis of LDPE Composites}

The storage modulus of LDPE and LDPE composite samples was investigated to improve steadily with the addition of CF contents. Figure 1 showed that the temperature dependence of the storage modulus of the control and composite samples. The values of storage modulus for LDPE composites were higher than that of pure LDPE throughout the temperature range. The storage modulus increased by $9.2 \%, 4.2 \%$, and $2.06 \%$, and $20 \mathrm{wt} \%$ of 20,10 , and $5 \% \mathrm{CF}$ into LDPE, respectively, compared to that of LDPE matrix (Figure 2). The loss factor $(\tan \delta$ ) of LDPE and LDPE composites are shown in Figure 2. There were significant changes in loss factor (the peak highest of $\tan \delta$ ) for 10 and $20 \mathrm{wt} \%$ CF into PP, compared to that of a lower loading level of CF and pure LDPE (Figure 2). The transition glass temperature (Tg) was determined from a maximum peak in $\tan \delta$ that increased with an increase of the CF loading level into LDPE. The value of $\mathrm{Tg}$ was about $120^{\circ} \mathrm{C}$ in the LDPE matrix, compared to that of $10 \mathrm{wt} \%\left(121.5^{\circ} \mathrm{C}\right), 10 \mathrm{wt} \% \mathrm{CF}\left(130^{\circ} \mathrm{C}\right)$, and $20 \mathrm{wt} \%\left(135.5^{\circ} \mathrm{C}\right)$ of 5,10 , and $20 \mathrm{wt} \% \mathrm{CF}$ into LDPE, respectively The presence of a higher content of CF may enhance the flexibility and reduces the molecular mobility of the LDPE polymer molecular chain.

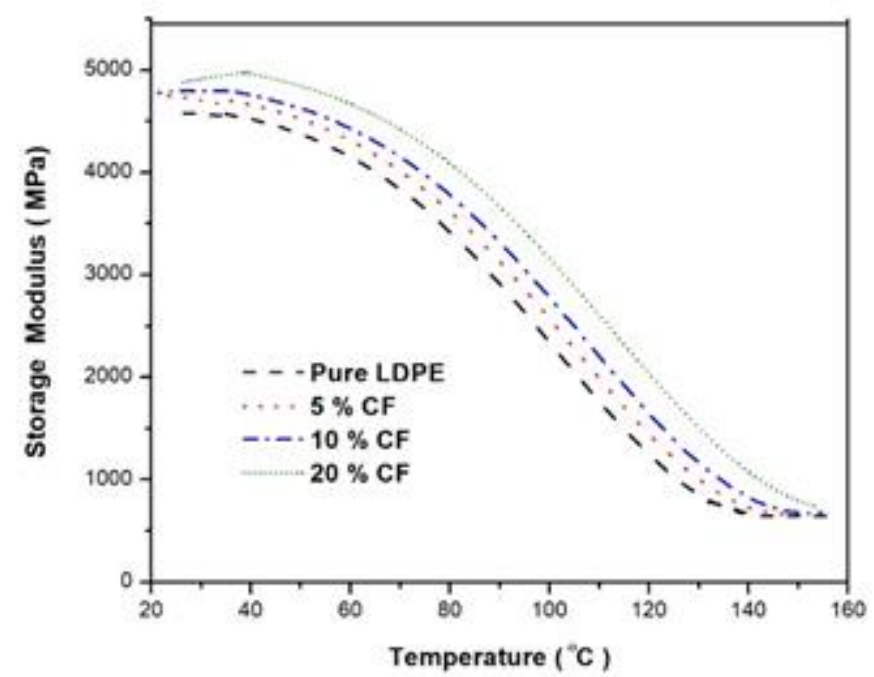

Figure 1. The storage modulus of LDPE and LDPE composites

\subsection{Thermal Analysis of LDPE and LDPE/CF Composites}

The results of thermal degradation for the LDPE matrix and LDPE/CF composite samples are shown in Table 2. $T_{\mathrm{i}}$ defines as the initial degradation temperature and is a relevant factor in determining the thermal stability. The maximum degradation temperature $T_{\max }$ and residue at $600^{\circ} \mathrm{C} \%$ are shown in Table 2 . The incorporation of $10 \mathrm{wt} \% \mathrm{CF}$ into LDPE can prominently increase both $T_{\mathrm{i}}$ and $T_{\max }$ of the LDPE composites by 99.7 and $52.8{ }^{\circ} \mathrm{C}$, respectively. The presence of the CF is to make more stability to the LDPE matrix and gives higher crosslinking between the CF fillers and the pure LDPE. Table 2 showed that $T_{\mathrm{i}}, T_{\max }$, and residual yield were 
increased by increasing the content of CF. Table 2 indicated that $T_{\mathrm{i}}$ was about $455.8^{\circ} \mathrm{C}$ while $\mathrm{T}_{\mathrm{i}}$ of 5, 10, and $20 \% \mathrm{CF}$ into LDPE was $477.5^{\circ} \mathrm{C}, 510.4{ }^{\circ} \mathrm{C}$, and $555.5^{\circ} \mathrm{C}$, respectively. Table 2 displayed that $T_{\max }$ of pure LDPE was $472.6^{\circ} \mathrm{C}$, compared to that of LDPE-20 $\mathrm{wt} \% \mathrm{CF}$ composite $\left(525.4^{\circ} \mathrm{C}\right)$.

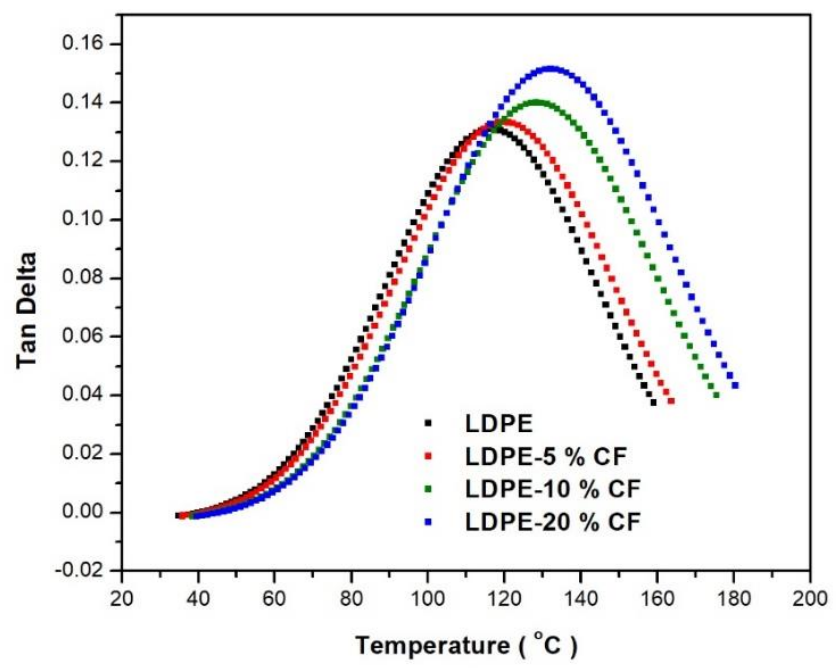

Figure 2. The loss factor ( $\tan \delta$ ) of LDPE and LDPE composites

Table 1 showed that the residue percentage of 5, 10, and $20 \% \mathrm{CF}$ into LDPE increased by $15.7 \%, 18.2 \%$, and 21.2 respectively, by comparing with that of pure LDPE (14.5\%). Figure 3 exhibited the Arrhenius plots for the activation energy $\left(E_{a}\right)$ for the decomposition of LDPE and LDPE composites. The effects of blend composition and compatibilisation on the $E_{a}$ of LDPE and LDPE composites are given in Table 2. The value of $E_{a}$ in 20\% CF /LDPE composites was 141.6 $\mathrm{KJ} \cdot \mathrm{mol}^{-1}$ while $E_{\mathrm{a}}$ for $10 \mathrm{wt} \%, 5 \mathrm{wt} \%$, and LDPE matrix was $123.8,124.2$, and 118.3 $\mathrm{kJ} \cdot \mathrm{mol}^{-1}$, respectively. It was seen that the higher addition $(10 \mathrm{wt} \% \mathrm{CF})$ into LDPE increased the $E_{a}$ in the LDPE matrix.

Table 2. Thermal properties of LDPE and LDPE composites

\begin{tabular}{ccccc}
\hline System & $\mathbf{T}_{\mathbf{i}} \pm \mathbf{0 . 1}\left({ }^{\mathbf{o}} \mathbf{C}\right)$ & $\mathbf{T}_{\mathbf{m a x}} \pm \mathbf{0 . 1}\left({ }^{\mathbf{0}} \mathbf{C}\right)$ & $\boldsymbol{E}_{\boldsymbol{a}}\left(\mathbf{K J} \cdot \mathbf{m o l}^{-\mathbf{1}}\right)$ & Residue yield at (\%) \\
\hline Pure LDPE & 455.8 & 472.6 & 118.3 & 14.5 \\
$5 \mathrm{wt} \% \mathrm{CF}$ & 477.5 & 474.5 & 124.2 & 15.7 \\
$10 \mathrm{wt} \% \mathrm{CF}$ & 510.4 & 499.3 & 123.8 & 18.2 \\
$20 \mathrm{wt} \% \mathrm{CF}$ & 555.5 & 525.4 & 141.6 & 21.4 \\
\hline
\end{tabular}




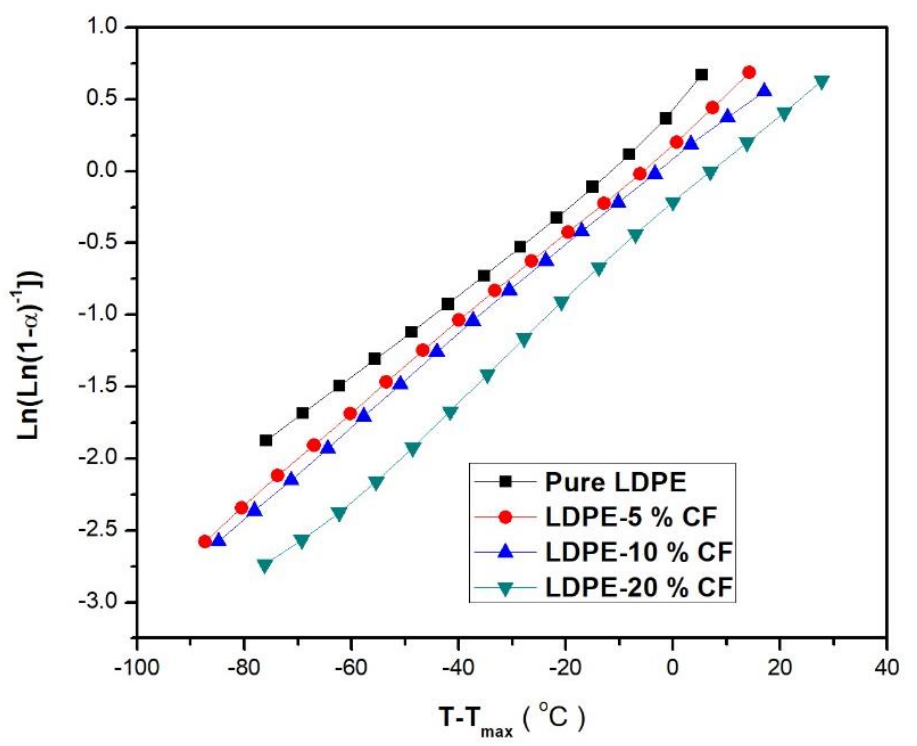

Figure 3. Arrhenius plots of calculating the activation energy for LDPE and LDPE composites

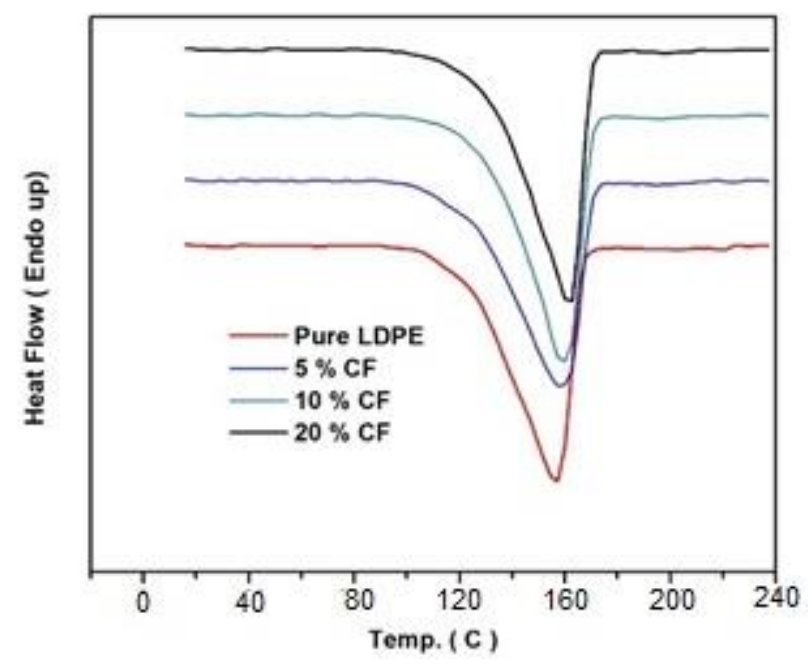

Figure 4. DSC thermogram curves of LDPE and LDPE composites

\subsection{Crystallisation Behavior of LDPE composites}

Thermal Properties of LDPE composites were analysed using DSC, and the thermogram curves were shown in Figure 4. The crystallinity degree of the LDPE composites was quantitatively measured by subtracting the filler mass contribution. From Table 3, the melting enthalpy $\left(\Delta H_{\mathrm{m}}\right)$ increased with increase in the CF content into LDPE. The $\Delta H_{\mathrm{m}}$ value of $20 \mathrm{wt} \% \mathrm{CF}$ into LDPE increased (195.2 J/g), compared to the lower contents $5 \mathrm{wt} . \%, 10 \mathrm{wt} . \%$, and pure LDPE (190.7 $\mathrm{J} / \mathrm{g}, 191.5 \mathrm{~J} / \mathrm{g}$, and $189.8 \mathrm{~J} / \mathrm{g}$ ). In the case of CF into LDPE, Tm shifted to a higher temperature $\left(161.7{ }^{\circ} \mathrm{C}\right)$, compared to that of $5 \mathrm{wt} \%, 10 \mathrm{wt} \% \mathrm{CF}$, and pure LDPE $\left(158.4{ }^{\circ} \mathrm{C}, 159.2{ }^{\circ} \mathrm{C}\right.$, and $155.5^{\circ} \mathrm{C}$ ), respectively. The high melting points can probably be attributed to the increase of LDPE matrix crystals. The crystallisation points of LDPE and LDPE composites showed no significant changes in LDPE and LDPE composites (Table 2). LDPE composites exhibited 
higher endothermic crystallisation points, compared with the LDPE matrix. 20 wt.\% filled LDPE showed a higher crystallinity (27.4\%) while LDPE crystallinity was $24.5 \%$.

Table 3. The results from DSC thermogram curves properties for LDPE and LDPE composites

\begin{tabular}{llll}
\hline The samples & $\boldsymbol{T}_{\mathbf{m}}\left({ }^{\circ} \mathbf{C}\right)$ & $\boldsymbol{\Delta H}_{\boldsymbol{m}}(\mathbf{J} / \mathbf{g})$ & $\boldsymbol{X}_{\mathbf{c}}(\%)$ \\
\hline Pure LDPE & 155.5 & 189.8 & 24.5 \\
LDPE / 5 \% CF & 158.4 & 190.7 & 24.8 \\
LDPE / 10 \% CF & 159.2 & 191.5 & 25.2 \\
LDPE / 20 \% CF & 161.7 & 195.2 & 27.4 \\
\hline
\end{tabular}

\section{CONCLUSIONS}

The effect of CF content in LDPE polymer has been investigated. It has been found that The higher values of CF fillers in LDPE improved the thermal and mechanical properties of LDPE. The LDPE composites showed higher tensile strength and modulus of elasticity compared to that of LDPE matrix. 20\% CF into LDPE was higher storage of modulus than that of pure LDPE. The LDPE composites with a higher loading (20 wt \%) of CF exhibited higher thermal stability by comparing with that of pure LDPE. From endothermic DSC curves, it is observed that the melting points, the melting enthalpy $\left(\Delta H_{\mathrm{m}}\right)$ and crystallinity points of LDPE composites increase as the $\mathrm{CF}$ content increase. Overall results confirmed that $\mathrm{CF}$ contents are more effective and reinforce the LDPE matrix.

\section{REFERENCES}

[1] M. Alidadi-Shamsabadi, T. Behzad, R. Bagheri, B. Nari-Nasrabadi, Preparation and characterization of low-density polyethylene/thermoplastic starch composites reinforced by cellulose nanofibers, Polym. Compos. 36(12) (2015) 2309-2316.

[2] S.A. Awad, E.M. Khalaf, Evaluation of thermal and mechanical properties of Low-Density Poly Ethylene (LDPE)-Corn Flour (CF) composites. Int. Journal ChemTech Research. 10(13) (2017) 230-235.

[3] S.A. Awad, E.M. Khalaf, Improvement of the chemical, thermal, mechanical and morphological properties of polyethylene terephthalate-graphene particle composites, Bull. Mater. Sci. 41(3) (2018) 67.

[4] P. Blaszczak, W. Brostow, T. Datashvili, H.E.H. Lobland, Rheology of low-density polyethylene+ Boehmite composites, Polym. Compos. 31(11) (2010) 1909-1913.

[5] S.A. Awad, Influence study of (Vitamin C) absorption on the mechanical properties of (Polyethylene terephthalate) drinking bottles. Journal of University of Anbar for Pure Science 5 (2011) $31-36$

[6] S. Ghafarizadeh, M. Fréchette, E. David, Fabrication and Dielectric, Mechanical, and Thermal Properties of Low-Density Polyethylene (LDPE) Composites Containing Surface-Passivated Silicon (Si/SiO2 Core/Shell Nanoparticles), Polym. Plast. Technol. Eng. 57(4) (2018) 327-334. 
[7] E.M. Khalaf, S.A. Awad, Improvement of Mechanical and Water Absorbance Properties of LowDensity Polyethylene (LDPE) by using White Kaolin Powder (WK). J. Adv. Chem. Sci. 3(1) (2017) 426-427.

[8] M. Goyal, N. Goyal, H. Kaur, A. Gera, K. Minocha, P. Jindal, Fabrication and characterisation of low density polyethylene (LDPE)/multi walled carbon nanotubes (MWCNTs) nano-composites, Perspectives in Science 8 (2016) 403-405.

[9] N. Gray, Y. Hamzeh, A. Kaboorani, A. Abdulkhani, Influence of cellulose nanocrystal on strength and properties of low density polyethylene and thermoplastic starch composites, Industrial Crops and Products 115 (2018) 298-305.

[10] E. Khalaf, S. Awad, Improvement of Chemical and Thermal Properties of Polyethylene Terephthalate (PET) by Using Multi-Walled Carbon Nanotubes (MWCNTs), International Journal of Materials Science and Applications 5(6) (2016) 297-301.

[11] S.A. Awad, E.M. Khalaf, Improvement chemical, thermal, and mechanical properties of Polypropylene by using corn flour, Usak University Journal of Material Sciences 6(1/2) (2017) 1525.

[12] S. Awad, E. Khalaf, Improvement, the Performance of Polyurethane (PUR), Y-290 Resin as Coating of Oil Pipeline by Using Multi-Walled Carbon Nanotubes (MWCNTs), Engineering and Technology Journal 35(8 Part (A) Engineering) (2017) 845-848.

[13] A. Luyt, J. Molefi, H. Krump, Thermal, mechanical and electrical properties of copper powder filled low-density and linear low-density polyethylene composites, Polym.Degrad. .Stab.91(7) (2006) 1629-1636.

[14] Y.A. Mubarak, R.T. Abdulsamad, Effects of microcrystalline cellulose on the mechanical properties of low-density polyethylene composites, J. Thermoplast. Compos. Mater. (2018) 0892705717753056.

[15] C. Reddy, C. Das, Propylene-ethylene copolymer filled nanocomposites: Influence of Zn-ion coating upon nano-SiO2 on structural, thermal, and dynamic mechanical properties, Polym. Plast.Technol. Eng. 45(7) (2006) 815-820.

[16] P. Roy, P. Surekha, C. Rajagopal, S. Chatterjee, V. Choudhary, Accelerated aging of LDPE films containing cobalt complexes as prooxidants, Polym. Degrad. Stab. 91(8) (2006) 1791-1799.

[17] K. Şirin, M. Balcan, F. Doğan. The influence of filler component on mechanical properties and thermal analysis of PP-LDPE and PP-LDPE/DAP ternary composites, Polypropylene, InTech, 2012.

[18] Z. Wang, M. Lu, H.-L. Li, X.-Y. Guo, SWNTs-polystyrene composites preparations and electrical properties research, Mater. Chem. Phys. 100(1) (2006) 77-81.

[19] S.A. Awad, E.M. Khalaf, Investigation of improvement of thermal and mechanical properties of polypropylene/nano clay composites, International Journal of Chemistry and Technology 2(2) (2018) 129-134.

[20] Q. Zhang, S. Rastogi, D. Chen, D. Lippits, P.J. Lemstra, Low percolation threshold in single-walled carbon nanotube/high-density polyethylene composites prepared by melt processing technique, Carbon 44(4) (2006) 778-785.

[21] M. Lisunova, Y.P. Mamunya, N. Lebovka, A. Melezhyk, Percolation behaviour of ultrahigh molecular weight polyethylene/multi-walled carbon nanotubes composites, European Polymer Journal 43(3) (2007) 949-958.

[22] [S.A. Awad, E.M. Khalaf, Evaluation of the photostabilizing efficiency of polyvinyl alcohol-zinc chloride composites, J. Thermoplast. Compos. Mater. (2018) 0892705718804585.

[23] [A. Diop, F. Mijiyawa, D. Koffi, B.V. Kokta, D. Montplaisir, Study of lignin dispersion in lowdensity polyethylene, J. Thermoplast. Compos. Mater. 28(12) (2014) 1662-1674. 